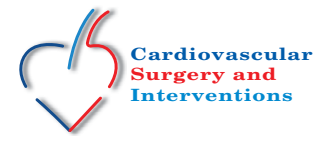

\title{
Successful coronary bypass surgery in a patient with hemophilia: A case report
}

\author{
Semih Murat Yücel (D), Serkan Burç Deşer (D), Mustafa Kemal Demirağ (D) \\ Department of Cardiovascular Surgery, Ondokuz Mayıs University Faculty of Medicine, Samsun, Turkey
}

Received: August 10, 2018 Accepted: August 29, 2018 Published online: April 24, 2019

\section{ABSTRACT}

Hemophilia is an X-linked congenital coagulation disorder characterized by increased tendency to bleeding. Hemophilia A is an X-linked disorder resulting from a deficiency in blood clotting factor VIII, a key component of the coagulation cascade. Perioperative management is very important in this patient population. In this report, we present a 78-year-old male case with hemophilia A who underwent coronary artery bypass grafting.

Keywords: Coronary artery bypass grafting, Factor VIII, hemophilia A.

Hemophilia is an X-linked congenital coagulation disorder characterized by increased tendency to bleeding. Hemophilia $\mathrm{A}$ is an $\mathrm{X}$-linked disorder resulting from a deficiency in blood clotting factor VIII, a key component of the coagulation cascade. Factor VIII deficiency is present in patients with hemophilia A, while factor IX deficiency is present in patients with hemophilia B. The first one is more common than the latter type of hemophilia. The incidence of hemophilia A is $1 / 10.000$ in the world. Recent improvements in the management of hemophilia A have increased the life expectancy in these patients and, currently, the life expectancy in the hemophilia A patients is similar to the healthy population. However, age-related cardiovascular diseases have also become more prevalent in these patients. Open heart surgery poses certain challenges in patients with hemophilia $A$, due to the requirement of cardiopulmonary bypass $(\mathrm{CPB})$ and heparinization for extracorporeal circulation. To overcome bleeding complications in the perioperative period, it is of utmost importance to identify preoperative factor levels and inhibitor levels and to administer factor replacement therapies. ${ }^{[1]}$

In this report, we present a male case with hemophilia $A$ who underwent coronary artery bypass grafting (CABG).

\section{CASE REPORT}

A 78-year-old male patient with hemophilia A was referred to the emergency department with severe chest pain. The patient underwent coronary angiography to diagnose acute anterior myocardial infarction. Diffuse three-vessel coronary artery disease was detected and the patient was advised to have CABG. His medical history revealed hemophilia A for six years, although there was no significant bleeding history during childhood and young adulthood. He underwent a right inguinal hernia repair operation six years ago. The patient was consulted to the hematology department due to a recurrent incisional hematoma. Factor VIII level was $11 \%$. The patient was diagnosed with hemophilia A and Factor VIII replacement was administered before discharge. $\mathrm{He}$ had also comorbidities including chronic obstructive pulmonary disease and hypothyroidism and he was using oral levothyroxine sodium $25 \mu \mathrm{g}$ once a day. The ejection fraction of the patient was $55 \%$. The hematocrit level was $38 \%$. The platelet count was $219,000 / \mu \mathrm{L}$ (reference range: $150,000-450,000 / \mu \mathrm{L}$ ). The international normalized ratio was 0.99 (0.9-1.2). Factor VIII level was 20\% (50-150). Factor VIII inhibitor was negative. The other biochemical laboratory test results were normal. The patient was

Corresponding author: Semih Murat Yücel, MD. Ondokuz Mayı Üniversitesi Tip Fakültesi Kalp ve Damar Cerrahisi Anabilim Dalı, 55220 Kurupelit, Samsun, Turkey. Tel: +90532-052 1151 e-mail: drsemihyucel@yahoo.com

Citation:
Yücel SM, Deșer SB, Demirağ MK. Successful coronary bypass surgery in a patient
with hemophilia: A case report. Cardiovasc Surg Int 2018;5(3):47-49.
with hemophilia: A case report. Cardiovasc Surg Int 2018;5(3):47-49. 
consulted to the hematology department. We did not perform thromboelastography, as our consultant hematologist did not order. One hour before the operation the patient received 3,000 IU Factor VIII intravenously. Factor VIII level reached 105\%. A written informed consent was obtained from the patient.

Median sternotomy was performed under general anesthesia. Intravenous heparin injection was done (300 IU/kg) after the harvesting of bypass grafts (left internal mammary artery and saphenous vein). The patient underwent four-vessel CABG. The highest activated clotting time (ACT) level was 854 sec. The temperature under $\mathrm{CPB}$ was $31^{\circ} \mathrm{C}$. Cross-clamp time was $53 \mathrm{~min}$, while $\mathrm{CPB}$ time was $100 \mathrm{~min}$. After CPB was terminated, protamine was administered to neutralize heparin. We used tranexamic acid at a dose of $10 \mathrm{mg} / \mathrm{kg}$ bolus, $1 \mathrm{mg} / \mathrm{kg} / \mathrm{h}$ infusion over eight $\mathrm{h}$. No cell-saver was used. The patient was administered one unit of fresh frozen plasma (FFP), while no platelet suspension was given. The operation was completed in a routine fashion.

The patient had a total of $560 \mathrm{~mL}$ drainage during perioperatively. He stayed in the intensive care unit for three days and underwent 1,500 IU Factor VIII replacement b.i.d. for the first four days postoperatively. Over the next six days, 1,000 IU Factor VIII replacement b.i.d. was performed. Factor VIII level was $47 \%$ on postoperative Day 10 . The patient was administered three units of blood transfusion and oral acetylsalicylic acid $150 \mathrm{mg}$ daily as of the postoperative first day. At the time of discharge, the hematocrit level was $32 \%$. There was no pleural or pericardial effusion or bleeding at any part of the body. He was discharged on postoperative Day 11 uneventfully.

\section{DISCUSSION}

Recent improvements in the management of hemophilia A have increased the life expectancy in these patients. The incidence of coronary artery disease has been increasing with increasing age in these patients as well as in the normal population. ${ }^{[1]}$ Interventional or surgical methods which can be applied carry a high risk of bleeding, as these patients are dependent on anticoagulant or antiaggregant therapies.

Throughout their professional lives, cardiovascular surgeons operate a very small number of patients with hemophilia A. Therefore, both surgeons and anesthesiologists may not have adequate experience on perioperative management of these patients. The World Hemophilia Federation recommends that, in hemophilia A patients undergoing a major surgery, the preoperative target level for Factor VIII should be 80 to $100 \%$ and these levels should be maintained in the first couple days after surgery. ${ }^{[2]}$ Of note, higher levels of Factor VIII may increase the risk of thrombosis in $\mathrm{CABG}$ and prosthetic valves. On the other hand, cardiovascular surgeons may experience difficulties in providing hemostasis due to major alterations in the hemostatic system caused by median sternotomy, full dose heparinization, CPB, hypothermia, postoperative thromboprophylaxis, and antiplatelet or anticoagulant drugs used.

Our case did not have any bleeding complications in the perioperative period. He was administered three units of blood and one unit of FFP. To reduce the risk of graft thrombosis, the Factor VIII dose administered was gradually reduced during the postoperative period. Since the coronary anatomy of the patient was not appropriate, off-pump surgery was not chosen. However, attempts to reduce blood trauma by applying moderate hypothermia and minimizing $\mathrm{CPB}$ equipment were made.

During the perioperative period of patients with hemophilia A, a team of surgeons, anesthesiologists, and hematologists should follow a multidisciplinary approach. ${ }^{[3]}$ The most important point to reduce bleeding is to ensure adequate preoperative preparation. In addition, the followings are the points to be addressed: avoiding hypothermia, performing off-pump surgery, if possible, keeping CPB time short, minimizing the use of $\mathrm{CPB}$ equipment, and avoiding strong aspiration to reduce the trauma of shaped components of the blood. In addition, in these patients, all necessary examinations regarding the coagulation system should be done preoperatively. The opinion of the hematologist must be taken in this context. It should also be remembered to the hematologist that open heart surgeries differ from other operations due to their possible adverse effects on the coagulation system. Blood products and clotting factors which can be used in the perioperative period should be thoroughly prepared. If these preparations are not made in accordance with a multidisciplinary approach, it may be impossible to manage bleeding complications. 
In conclusion open heart operations of patients with hemophilia A have significant differences and risks from other operations. Even the most experienced heart surgeons and anesthesiologists encounter these patients very rarely in their professional lives. The multidisciplinary case management that will be performed according to the recommendations of the hematologist will reduce the bleeding complications to a minimum. It should be kept in mind that excessive replacement of the Factor VIII to reduce bleeding complications may increase the risk of bypass grafts and prosthetic valve thrombosis.

\section{Declaration of conflicting interests}

The authors declared no conflicts of interest with respect to the authorship and/or publication of this article.

\section{Funding}

The authors received no financial support for the research and/or authorship of this article.

\section{REFERENCES}

1. Barillari G, Pasca S, Erice F, Livi U. Successful double bypass in a patient with severe hemophilia A: a case report. J Thromb Thrombolysis 2012;33:193-6.

2. Kanellopoulou T, Nomikou E. Replacement therapy for coronary artery bypass surgery in patients with hemophilia A and B. J Card Surg 2018;33:76-82.

3. Boğa $M$, Yağdı $T$, Diş̧̧igil B, Büket $S$. Coronary artery bypass grafting in a patient with Hemophilia B (Case report). Turk Gogus Kalp Dama 1999;7:414-6. 